\title{
DIOS, LAS SECTAS Y LOS INSECTOS
}

Alberto Sauret*

Dejar de creer en Dios permite creer en cualquier cosa: Chesterton

\section{${ }^{6}$ La Declaración Americana de la}

Independencia fue precedida y preparada por un acontecimiento mayor todavía: La Declaración de la Independencia intelectual que encontramos en los teóricos del siglo XVIII. Ahí fue donde la razón proclamó primeramente su poder y su derecho a regir la vida social del hombre. Se había emancipado de la tutela del pensamiento teológico; podía valerse por sí sola." 1

Sin embargo, la radicalidad de la emancipación sólo es aparente, y ello se percibe en el modo de interpretar lo histórico como mera crónica de acontecimientos - sin mayores diferencias ontológicas con las narraciones de Tucídides o Heródoto- no obstante una idea de tiempo progresivo. Temporalidad que implica un determinismo sustancialista -donde sobrevive la noción teológica de cosmos cerrado- es decir, una concepción no problemáticạ de relacionar el presente humano con su futuro.

Dicho de otro modo, la idea de progreso encierra una incomprensión de la historicidad; no ve la vida como algo orgánico, sino que separa fondo - progresivo- de apariencias intercambiables a voluntad: 'opciones'. Pero "nuestra duración no es un instante que sustituye a otro instante", dirá Bergson. "La duración es el progreso continuo

* Departamento Académico de Estudios Generales, ITAM.

${ }^{1}$ Ernst Cassirer, El mito del Estado, 1972, 1a. r., México, FCE, p. 198. 


\section{ALBERTO SAURET}

del pasado que carcome el porvenir y se hincha al avanzar. Dado que el pasar aumenta sin cesar, se conserva también indefinidamente." "Esta supervivencia del pasado hace imposible que una conciencia atraviese dos veces la misma situación. (...) Por eso nuestra duración es irreversible." 2

La razón nos ha conducido ante la evidencia de que el futuro no tiene formas predeterminadas, su principal aspecto es la incertidumbre. Pero el horror al vacío provocado por esta apertura a lo desconocido convocará los favores de la 'capacidad fabuladora' para restituir la protección de lares, penates y demás tutores de la sociedad cerrada.

La superstición de un progreso ineluctable entraña la enajenación de ver como proceso que continúa la determinación del orden de la physis lo que es propio del régimen del nomos $\mathrm{y}$, por tanto, no verse como productor de todo artificio inscrito en el tiempo histórico, que es el tiempo secular de las obras humanas.

La completa alienación respecto de la propia creación se manifiesta con toda su esquizofrenia cuando comprobamos la coexistencia de la suposición determinista de Adam Smith -"la búsqueda del beneficio individual conduce al bienestar general"- con la concepción ética pro-

32 testante -agente secularizador de los órdenes legal y político- totalmente ajena a la idea de la ley natural en la que se basa la adecuación de las categorías aristotélicas y tomistas.

El siglo XVIII forja las nociones del pensamiento histórico pero es incapaz aún de aplicarlas autorreflexivamente, a esta tarea la emprenderán algunos hombres del siglo XIX y del nuestro, pero la 'conciencia histórica de la crisis' es vital antes que intelectual y empujará a muchos a un desesperanzado y reactivo nihilismo -tan irracional y determinista como el puro optimismo progresista- o a variantes escapistas del fatalismo.

"Hay un cuadro de Klee que se llama Angelus Novus. En él se representa un ángel que parece como si estuviese a punto de alejarse de

${ }^{2}$ Henri Bergson, La evolución creadora, 1962, Buenos Aires, La pléyade, p. 63 . 
algo que lo tiene pasmado. Sus ojos están desmesuradamente abiertos, la boca abierta y extendidas las alas. Y éste deberá ser el aspecto del ángel de la historia. Ha vuelto el rostro hacia el pasado. Donde a nosotros se nos manifiesta una cadena de datos, él ve una catástrofe única que amontona incansablemente ruina sobre ruina, arrojándolas a sus pies. Bien quisiera él detenerse, despertar a los muertos y recomponer lo despedazado. Pero desde el paraíso sopla un huracán que se ha enredado en sus alas y que es tan fuerte que el ángel ya no puede cerrarlas. Este huracán lo empuja irreteniblemente hacia el futuro, al cual da la espalda, mientras que los montones de ruinas crecen ante él hasta el cielo. Ese huracán es lo que nosotros llamamos progreso." 3

El torbellino del progreso ha desguazado todas las instituciones: familia, sociedad, Iglesia son presas de la atomización sectaria. En este proceso de disolución secular me parece reconocer tres factores coadyuvantes.

Dice Paul Tillich: "El cristianismo es una religión revelada pero filosóficamente desmitologizada." ${ }^{4}$ Es decir, en primer lugar que la teología opera un efecto contraproducente respecto de la fe, pues en cierto sentido su penetración racional en el mito implica el efecto secundario de una 'descomposición' del misterio, o sea un allanamiento por y en los límites de la razón. La filigrana teológica en muchos casos estará originada en la necesidad de dar respuestas que preserven a la ortodoxia de los embates de la multitud de interpretaciones heréticas del dogma durante la Edad Media. Fermentos que prefiguran la dinámica del sectarismo introducida por Lutero, con el que comenzará el desgajamiento de la comunidad medieval y la progresiva desintegración de la grey cristiana. "Si Europa se define por una sucesión de cismas, si sus glorias se reducen a un desfile de heterodoxias, es a él a quien se lo debe", afirma Ciorán. "Si tuviera sentido establecer metafóricamente el nacimiento de la Edad Moderna, podría afirmarse que

${ }^{3}$ Walter Benjamin, Discursos interrumpidos, 1982, Madrid, Taurus, t. I, p. 178-9.

${ }^{4}$ El futuro de las religiones, 1976, Buenos Aires, Megápolis, p. 105. 


\section{ALBERTO SAURET}

ocurrió [el 31 de octubre de 1517 cuando] Lutero clavó a martillazos el catolicismo medieval en las puertas de la iglesia." "El sentimiento religioso ha despertado de la asfixia en que había vivido desde la muerte de los mil dioses paganos y los nuevos cauces los busca empujado por las nuevas contradicciones del tiempo."5

En segundo lugar, la fusión y a veces confusión de los reinos, consecuente de la institucionalización política del cristianismo introducida por Constantino. Agreguemos aquí que el cisma provocado por el antiguo monje agustino será radicalizado por el frío e implacable espíritu de Calvino, que dotará a las nuevas iglesias de una administración normada por un criterio administrativo que adopta nuevos valores pragmáticos, como libre cambio, ahorro, inversión.

En tercer lugar, y en relación con lo anterior, la irrupción avasalladora de la racionalidad instrumental, que ha provocado un alejamiento de los problemas fundamentales, pauta para elucidar principios y fines que adecúen el obrar humano en el ámbito de la totalidad. La secularización definitiva no tiene origen en la razón teórica sino en la racionalidad práctica, inmediatista, disgregante de los intereses ordinarios. Las múltiples formas de racionalización instrumental han conducido a la 'muerte de Dios' y ahora a la fabricación de ídolos a la medida.

El conflicto entre religión y modernismo ha provocado diversas reacciones, de las que me interesa mencionar ejemplos en contraste.

En un extremo encontramos una posición tradicionalista como la del poeta anglocatólico T. S. Eliot, quien sostiene: "Debemos abandonar la idea de que el cristianismo ha de contentarse con la libertad de culto y con no sufrir trabas por causa de su fe. Por fanático que parezca el anuncio, el cristiano no puede contentarse con nada menos que una organización cristiana de la sociedad; que no es la misma cosa que una sociedad en la que el fin natural del hombre-la virtud y el bienestar en la comunidad-se lo reconoce para todos, y el fin sobrenatural -la beatitud-para quienes tienen ojos para verlo."

${ }^{5}$ Blas Carmona, Los profetas sospechosos, 1980, Barcelona, Gedisa, p. 18 y 8 . 
Esta postura encuentra una mayor radicalidad y explicitación en Hillaire Belloc, para quien a diferencia de la mayoría que atribuye el fenómeno de la crisis europea a la exclusiva consecuencia del progreso, la ciencia, las máquinas, el industrialismo o el espíritu burgués, él la iguala con la crisis de la cristiandad, destacando la incidencia de la ruptura protestante en el proceso. "El gran efecto de la Reforma fue el aislamiento del alma (...) de él emanan todas sus consecuencias"; 6 "significa una pérdida del sustento colectivo, del sano equilibrio producido por la existencia común, la certidumbre pública y la voluntad general.".7

Contra la opinión dominante durante los últimos siglos, Belloc reivindica la plenitud espiritual de la 'Auténtica Edad Media' de los siglos XI, XII y XIII. "Lo que llamamos capitalismo surgió, directamente y en todas sus ramificaciones, del aislamiento del alma." 8

Dice este autor que la expresión 'punto de vista católico de la historia' es moderna y falsa, mientras exhorta a "la conciencia católica de la historia (...) conocimiento íntimo mediante la identidad", advirtiendo que "Europa volverá a la Fe o perecerá". "La Fe es Europa. Y Europa es la Fe", significa para Hillaire Belloc: "Nuestra estructura europea (...) sólo perdurará en el molde de la Iglesia Católica." 9

El contexto de la obra de Belloc-aparecida originalmente en 1924 es el del movimiento ecuménico, iniciado a principios del siglo con el propósito de atraer a las iglesias protestantes para concertar una reunión que conduciría al establecimiento del Consejo Mundial de Iglesias en Ginebra, inmediato a la Segunda Guerra.

La transición del feudalismo al orden burgués acarreará la Reforma en apoyo a las nuevas clases progresistas. Dice R. H. Tawney: "Bautizada en las estimulantes aguas de la teología calvinista, la vida comercial, considerada alguna vez peligrosa para el alma, adquiere una nueva santidad. El trabajo no es solamente un recurso económico, es un fin

${ }^{6}$ Hillaire Belloc, Europa y la fe, 1967, Buenos Aires, Losada, p. 258.

${ }^{7}$ Ibid., p. 262.

${ }^{8}$ Ibid., p. 267.

${ }^{9} \mathrm{Ibid} .$, p. 270. 


\section{ALBERTO SAURET}

espiritual. La avidez, aunque peligrosa para el alma, es una amenaza menor que la pereza (...) la búsqueda de riquezas, que alguna vez se temió por enemiga de la religión, era ahora bienvenida como su aliada."10 La Iglesia católica, en cambio, junto con los valores medievales defenderá el feudalismo rural, por lo que la burguesía reconocerá un enemigo en el clero. El capitalismo, el racionalismo y la Revolución Francesa harán replegar a la Iglesia en una actitud conservadora y defensiva.

Las 'contradicciones culturales del capitalismo' empujarán primero a los teólogos de los países protestantes, pero la industriosidad moderna ha sacudido todo el orbe. Hoy la contemporización es respuesta a un clamor de salvación inminente en un mundo que se autodestruye. Por eso, mientras que en los pasados siglos el protestantismo fue más progresista que el catolicismo, hoy puede observarse un fenómeno inverso, pues "resulta más fácil para la Iglesia católica desprenderse de estructuras capitalistas, a las que nunca aprobó del todo, que a las iglesias luteranas comprometidas con la burguesía norteamericana decadente". ${ }^{11}$

En 1943, Pío XII autorizará una mayor libertad a los eruditos católicos para el estudio de la Biblia. Otra forma de reacción al modernismo por parte de la institución eclesiástica, también de inscripción protestante, será la que Juan XXII bautizara como aggiornamento, que significa 'puesta al día', no como capitulación sino como approfondimento: profundización y actualización del pensamiento teológico (escrutación y profetismo de los Evangelios sobre las novedades acaecidas en el tiempo del hombre).

Con un espíritu que inusitadamente expandía la actitud abierta por León XIII en la Encíclica Rerum Novarum -que entre otros reclamos asimilara los del Manifiesto comunista-el Papa Juan señalaba que el aggiornamento "trataría de adoptar, en su síntesis, lecciones aprendidas de la experiencia secular. Se preocuparía más de responder a las necesidades de los hombres modernos y a sus problemas que por observar

${ }^{10}$ John Cogley, 1969, Caracas, Monte Ávila, p. 105.

${ }^{11}$ Enrique Marroquín, La contracultura como protesta, 1975, México, Joaquín Mortiz, p. 111. 
tradiciones que ya no quieren decir nada. Buscaría incorporar a una teología revitalizada las ideas de disciplinas no teológicas". ${ }^{12}$

La confrontación con el espectro abierto por la historia y la sociología de las religiones hará pensar que al alejarse del mundo sacro de las religiones animistas, con sus espacios y tiempos sagrados, el cristianismo se encuentra liberado de las formas de una religión, y por tanto en mejores condiciones de comprender su mensaje esencial.

El nuevo espíritu hermenéutico con que los exégetas abordan los mitos bíblicos establecerá paralelismo y continuidad con lo que entienden como urgencias de la hora y vicisitudes de los primeros tiempos del cristianismo. Al principio, dirán, el mayor problema consistió en liberar la revelación cristiana de los rígidos marcos de la cultura semita, destacando las dificultades de San Pablo para fundar comunidades cristianas entre los judíos helenizantes de la diáspora. Tendencias conservadoras identificarán al cristianismo con una cultura, pero el primer concilio de Jerusalén determinará que la iglesia no se encuentra limitada por ninguna cultura en particular, sino que es católica, es decir, universal. Y San Pedro cambiaría su residencia a Roma precisamente en aras de la universalidad.

Desde Constantino y durante la Edad Media, al volverse juridicista y organizativa, la iglesia, católica y apostólica, se conformará romana, no sólo por reconocer el primado pontificio sino por respaldar al carolingio, reedición del antiguo imperio; por lo que entonces, su labor misionera de cristianizar a los pueblos paganos implicará en occidentalizarlos.

No muy lejos de Teilhard de Chardin, que profetiza una cultura cósmica, algunos teólogos postconciliares manifestarán que ante la inminencia de la nueva cultura universal, la Iglesia tendrá la única oportunidad de ser 'católica' de verdad, admitiendo el pluralismo cultural en su seno, para lo cual deberá desoccidentalizarse.

El temor ante una asimilación disgregante de las obras inscritas en el tiempo histórico, secular, devastador conducirá al refugio de la inmu-

12 John Cogley, op. cit., p. 225. 


\section{ALBERTO SAURET}

tabilidad mítica: semper idem, es decir, siempre igual, sin cambios será el lema del cardenal Ottaviani, líder del sector conservador en el Segundo Concilio Vaticano.

Pero es que el mismo aggiornamento no fue sino la reacción autopreservativa de una iglesia resquebrajada tanto en lo interno como exteriormente, y que Pablo vi atribuyera a la 'traición de los clérigos'. Mientras proliferan disensiones intestinas como el Opus Dei, Una Voce, los Silenciosos de la Iglesia, los pentecostistas católicos, las comunidades de base, los sacerdotes obreros, los diversos movimientos de Acción Católica o los cristianos marxistas, tendencias tan divergentes que casi parecen sectas internas, su exterior resiente el embate de 'fermentos carismáticos' que la desgarran. Por un lado con la abdicación de autoridad de los integristas, por otro con el horizontalismo de los progresistas, cuya acción social y política relega la dimensión vertical del anuncio de la fe.

Aunque de diferentes modos, estos fenómenos acusan la irrupción del movimiento teológico protestante llamado de 'la muerte de Dios'. Un divulgador del mismo, el Dr. John Robinson, que fuera obispo anglicano de Woolwich, dirá en 1963: "Los hombres no pueden seguir creyendo en la existencia de un Dios entendido como una Persona sobrenatural, tal como la religión lo ha presentado siempre." Su libro Honest to God vendió más de un millón de ejemplares en todo el mundo y sería traducido al francés con un título más significativo aún respecto de la 'furia desacralizadora' de la que participa: Dieu sans Dieu. (Toda una avanzada en la línea de la realidad virtual, que nos enseña a prescindir del original por el remedo.)

Esta revisión del 'cristianismo clásico' preconizada por Robinson abreva en la superación de lo 'mitológico' indicada por Bultmann, de lo 'sobrenatural' según Paul Tillich y de lo 'religioso' como lo entiende Dietrich Bonhoeffer.

Mientras que secularización es un término descriptivo que denota la constatación de un fenómeno, secularismo refiere un concepto normativo, es decir, conciencia, aceptación y decisión de continuidad del proceso reconocido. Por lo cual, secularismo implica en cierto modo 
una dialéctica de autodivinización, pues el hombre se convierte en exclusivo centro de referencia y medida.

Con Feuerbach la teología se transformará en antropología, para Marx y Nietzsche el ateísmo es condición para el crecimiento del hombre. En palabras de Harvey Cox (The Secular City, 1965, New York, Best Seller de la teología radical, representativo de una religiosidad inmanente inspirada en los teólogos de la muerte de Dios, donde lo sagrado ya no tiene referencia con lo divino), se trata de asumir "un proceso histórico irreversible, en el que la sociedad y la cultura se hallan liberadas de la tutela del control religioso y de concepciones metafísicas del mundo demasiado estrechas".

Recogiendo palabras de una homilía de Pío XII, Massimo Introvigne reconoce la noción actual de lo sagrado como resultante de un proceso histórico que puede sintetizarse en cuatro momentos, con los antecedentes: 1. Cristo sí, Iglesia no; 2. Dios sí, Cristo no; 3. Religión sí, Dios no. ${ }^{13}$

"En el mundo occidental estos movimientos modernistas han conducido al establecimiento de sociedades de cultura moral y de la Unión Humanista y Moral Internacional; asociaciones que ya ni siquiera aceptan la designación de 'religiosas'. (...) Según (un) dirigente contemporáneo de la Cultura Moral, los que eligieron el camino del modernismo optaron por la 'dignidad sin dogma'."14

Secularización, desacralización, desmitologización, que han minado la teología católica, provocarán que el jesuita alemán Karl Rahner haciéndose cargo de la crisis hable del 'Occidente postcristiano' en el que los nuevos cristianos liberados de su responsabilidad cultural constituyen la 'iglesia de la diáspora'. (Quizá no sea inoportuno recordar que simbolo significa 'lo que une' y diabolos, 'lo que desune'.)

La desmitologización procura que los enunciados de la fe proclamados en otro tiempo sean comprensibles y aceptables por el hombre de hoy. Pero la empresa demanda varias consideraciones. En primer lugar, lo dicho, que 'comprensión' y 'aceptación' atentan con reducir

${ }^{13}$ Inuovi culti, 1990, Milán, p. 14.

14 John Cogley, op. cit., p. 218. 


\section{ALBERTO SAURET}

la religión a los límites de la razón y, en consecuencia, a horadar sus cimientos, es decir, al ateísmo o en el mejor de los casos a esa deidad que Pascal llamara con desdén, 'el Dios de los filósofos'.

Pero además, reclamos del tipo: "La idea de Dios y la misma palabra Dios necesitan un replanteo. Quizás hagan falta palabras completamente nuevas", efectuados por quienes se autodenominan 'ateos cristianos ${ }^{15}$ no dejan de ser un tanto absurdos, pues las palabras para referirse a Dios siempre serán inadecuadas tomadas en sentido llano, la vocación exige un lenguaje analógico, por lo que el solo hecho de modificar la terminología poco o nada habrá de significar. Quizá la carencia de nombres sea tan sólo apariencia de la verdadera ausencia, como es la falta de experiencias de lo sagrado.

"Occidente no sólo ha reprimido lo numénico, lo irracional o lo infrarracional. (...) También ha reprimido, y acaso con mayor fuerza lo suprarracional, es decir, la mística y la metafísica. El ateísmo materialista niega la realidad objetiva de todo lo que no sea verificado con los sentidos o sus prolongaciones." 16

Monseñor Roger Etchegaray, a la sazón arzobispo de Marsella, al término de la asamblea plenaria del episcopado, en Lourdes, en 1975, dirá: "En el momento en que nuestra ciudad secular se vuelve cada vez más irrespirable (...) tiene una necesidad desesperada de la Palabra de Dios, y una Iglesia que no tiene ya más qué decir sino aquello que el hombre puede aprender por sí mismo no tendrá pronto ya nada qué decir a este hombre." 17

Pero si, presas del desconcierto y la incertidumbre las iglesias padecen de apofantismo, las sectas prodigan respuestas claras y sencillas para las preguntas elementales que el hombre no deja de formularse: ¿Quién soy? ¿De dónde vengo? ¿A dónde voy? ¿Para qué estoy?

"Una juventud desorientada y ávida de verdad absoluta se sentirá atraída por las sectas utopistas: los Hijos de Dios, los Discípulos de Krishna, los pioneros de la Nueva Era. (...) Los angustiados serán

${ }^{15}$ Ibid., p. 156.

${ }^{16}$ Enrique Marroquín, op. cit., p. 104.

${ }^{17}$ Alain Woodrow, Las nuevas sectas, 1986, 2a., México, FCE, p. 22. 
seducidos por las sectas milenaristas: los Adventistas, los Testigos de Jehová, los Mormones. Tentarán a los sedimentos de lo maravilloso las sectas medicinantes: los movimientos cuyo fin es despertar, el pentecostismo, los Tres Sagrados Corazones, el Cristo de Montfavet. Los adeptos de lo oculto se volverán al espiritismo, la astrología, la magia, el satanismo. Las sectas cientifistas convencerán a los racionalistas: la Ciencia cristiana, la Cienciología, la Teosofía. Atraerán a los orientalistas las sectas esotéricas: la meditación trascendental, la misión de la luz divina, el budismo zen, el vudú..."18

La constatación del fenómeno hará que Ernst Jünger reflexione: "Se producen, como bajo un cielo divino inferior, un número inabarcable de religiones sustitutorias. Incluso puede decirse que por el destronamiento de los supremos valores, todos y cada uno ganan la posibilidad de la iluminación y dación de sentido cúlticas. No sólo las ciencias de la naturaleza se introducen en ese papel. Las concepciones del mundo y las sectas prosperan; es un tiempo de apóstoles sin misión."19

Los nuevos movimientos religiosos y pararreligiosos aparecidos en el mundo son innumerables y diversos. Nos detendremos en algunas consideraciones. En primer lugar con la constatación de que -como obedeciendo a las observaciones de Nietzsche, de que la irracionalidad reprimida estalla por entre los resquicios del orden racional- la mayor aparición de sectas - algunas satánicas, como la de Mason- y fenómenos emparentados de esoterismo, brujería y mancias han tenido lugar en la zona de California flanqueada por las más importantes universidades y especialmente en el Silicon Valley, invernadero de la tecnología más sofisticada.

Hoy casi todas las universidades cuentan con un departamento de estudios religiosos, en la mayoría de los casos creado a petición de los estudiantes, pero en esto fue pionera la Universidad de Santa Bárbara en 1964.

${ }^{18}$ Ibid., p. 12.

${ }^{19}$ Ernst Jünger, Martin Heidegger, Acerca del nihilismo, 1994, Barcelona, Paidós, p. 42. 


\section{ALBERTO SAURET}

En Estados Unidos el movimiento contracultural más importante de los años 50 fue el beatnik. El 'grueso' (to be hip) llamará al 'alivianado' más tierno de la próxima generación, hippie. Los hippies se convertirán en yippies cuando se politicen en Berkeley.

Siguiendo a Jack Kerouac, uno de los principales portavoces de aquel movimiento ( $O n$ the Road), cuando dice que la beat generation se caracterizó por una profunda religiosidad, Enrique Marroquín, sacerdote claretiano que al momento de escribir el libro es catedrático en el Instituto Superior de Estudios Eclesiásticos, reflexionará: "La teología actual valora lo que denomina 'signos de los tiempos' (...) reconocidos como 'lugares teológicos'. (...) Para mí el movimiento hippie fue uno de estos 'signos' proféticos, pese a la inmadurez en que vivieron. Será labor nuestra aprender humildemente de ellos, en sincera escucha, pero con conciencia crítica, para discernir entre las manifestaciones auténticas de la nueva cultura, y las ilusiones propias de su juventud irreflexiva o de su alocada imaginación alucinada."20

El anarquismo beatnik contendrá caracteres violentos, la revuelta hippie se caracteriza por pacifista, pero también y marcadamente por antiautoritaria. Sus manifestaciones sociales, políticas y religiosas se exhiben ostentosamente contra toda institución oficial. Paradójicamente, toda esta rebeldía iconoclasta en poco tiempo se esfumará, dando lugar a nuevas oleadas que si bien mantienen la ruptura con las religiones oficiales se mostrarán dóciles ante extraños profetismos. (Por cierto, justo cuando el cristianismo se ha vuelto más renuente a hablar de ángeles, demonios y lo sobrenatural en general, ha cobrado un auge extraordinario el interés por lo extraordinario: astrología, magia, espiritismo, parapsicología, telepatía, reencarnación, transmigración...)

"Después de haber impugnado todas las formas de autoridad en 1968, he aquí una juventud que acepta la disciplina más rígida, la ascesis más total, el abandono de su voluntad y de su juicio en manos ajenas. Abandonando las Iglesias, pónese a adorar nuevos dioses, abrazando para mayor gloria de Krishna, las mismas virtudes de pobreza,

${ }^{20}$ Op. cit., p. 113. 
de castidad y de obediencia que consideraba anticuadas y ridículas entre los cristianos. (...) Abandono del sentido crítico, abdicación de la libertad: dos características inquietantes de cierta juventud, que llevan consigo no sólo un retroceso de lo político sino un avance de la derecha. Y sin un mínimo de discernimiento, queda el camino abierto a todas las recuperaciones, las manipulaciones, incluso los fascismos." 21 Comportamiento que parece inscribirse en la sentencia de Dostoievski en El gran inquisidor: "No existe para el hombre, que se mantiene libre, preocupación más constante, más punzante que la de buscar un ser ante quien inclinarse."

"Yo puedo convencer a cualquiera de cualquier cosa si se lo repito con bastante insistencia y si el sujeto no tiene otra fuente de información": 'apotegma' de Charles Mason que sirve también para ejemplarizar el ascendente sobre sus congregados de personajes como los líderes del suicidio colectivo del Templo del Pueblo en Guyana (un millar), la matanza de Waco y la inmolación de los miembros de la Orden del Templo Solar en Francia, Suiza y Canadá, convencidos de que matando sus cuerpos terrícolas liberarían a sus almas para que volasen a un planeta del sistema de Sirio, su lugar de origen. El periódico de hoy da la noticia de otro aparente suicidio de 39 personas integrantes de la secta Heaven's Gate en San Diego para partir de este mundo hacia un nuevo nivel de existencia en un ovni que llegó a la Tierra con el cometa Hale-Bopp, como lo anunciaran por Internet.*

Pero autoritarismo, paternalismo y fundamentalismo son evidentes en un fenómeno de mucho mayor envergadura como es la heteróclita Asociación para la Unificación del Cristianismo Mundial (llamada

${ }^{21}$ Alain Woodrow, op. cit., p. 30.

* Este texto fue redactado durante la Semana Santa de 1997 (en la ex Hacienda de Santo Domingo de Tultenango). Creo que son pertinentes los paralelismos históricos entre nuestro momento y la 'huida de la razón' experimentada en la Europa próxima al fin del primer milenio y posteriormente aterrorizada por las muertes masivas cobradas por la peste (epidemia reelaborada literariamente por Camus para simbolizar la plaga moderna de la guerra total, que tiene por antecedente a Nosferatu). 


\section{ALBERTO SAURET}

también Iglesia de la Unificación, o Pioneros de la Nueva Era), cuyos 'principios divinos mezclan algunas simplificaciones bíblicas, cosmología taoísta y cientificismo. Su fundador, el Reverendo Sun Myung Moon -hombre con enormes ambiciones de dinero y poder-declararía: 'Soy el más grande de los santos'; 'soy más grande que el mismo Jesús.'22

Bergson decía que los orígenes de la técnica y la ciencia estaban en las fórmulas rituales de la magia. Con el desarrollo de la ciencia experimental se ampliará el tráfico en el camino inverso, es decir, de lo racional a lo oculto -como indicara Koyré, fue mucho mayor la alquimia en el Renacimiento que durante la Edad Media.

Los apareamientos serían incontables, pero para nuestros propósitos sólo nos interesa trazar una línea entre algunas de las más resonadas nuevas bodas de la ciencia con el misterio, como son: la Ciencia cristiana, nacida en Nueva Inglaterra en la década de 1860, que mezcló algunas teorías científicas y corrientes filosóficas en boga en la época impregnada de positivismo, pero también con fermentos vitalistas de origen romántico. La Cienciología, fundada en California en 1954 por Ron Hubbard, que mortificado por ser un mediocre autor de ciencia-ficción, llegaría a la conclusión, según confiesa, de que "si se quiere realmente tener un millón de dólares, en vez de pasarse la vida empleado a cinco centavos la línea, la mejor solución será fundar una iglesia". ${ }^{23}$ Esta iglesia también es una próspera industria dedicada a producir instrumentos electromecánicos correctores de las 'zonas erróneas' del individuo.

Algo más interesante es el movimiento originado en la década de 1960 con el nombre de Gnosis de Princeton, en el que participan miles de estudiosos, incluidos varios premios Nobel, que a partir de teorías de la ciencia positiva sobre el azar y la necesidad o el orden y el desorden arriban a construcciones ideológicas de índole metafísica, como las referidas a las relaciones entre materia y espíritu, finalidad de la evolución, 'conciencia' del universo y hasta 'Dios' como Inteligencia que

${ }^{22}$ Ibid., p. 157.

${ }^{23}$ Blas Carmona, op. cit., p. 122. 
anima el cosmos. Fenómeno que hiciera exclamar a Arthur Koestler: "Es asombroso advertir cuántos físicos se interesan actualmente en la percepción extrasensorial. ¡Hoy en día los físicos son místicos!”

Husserl y Bergson serían de los principales impugnadores de la tajante separación conceptual entre sujeto y objeto en la que se basa la metodología científica, para fundar la problematización filosófica. Procurando una mejor correspondencia entre 'el pensamiento y lo moviente', Bergson acude a la alusión metafórica, y Husserl con su método fenomenológico reemplaza la definición por la descripción, que involucra a la conciencia activa del sujeto cognoscente en la situación concreta. Una de sus principales objeciones al racionalismo consistirá en mostrar que Descartes cuando pretende hacer tabula rasa con la tradición, no puede evitar pensar en un lenguaje que es inveterado producto de ella y con éste introducir la inmovilidad sustancialista de los conceptos heredados.

Descartes y sus sucesores constructores del racionalismo moderno, al trasladar el centro de la reflexión a la conciencia subjetiva echarán por tierra la filosofía realista para reemplazarla por una gnoseología cuyo criterio de certeza estrangula el concepto de lo real hasta lo esquemático. En nuestros días, Edgar Morin hará planteamientos epistemológicos críticos al sostener que una ciencia sin consciencia, como la que modela nuestras vidas, es resultado del mito de la objetividad por el que el sujeto cree contemplar lo que es como espectador neutral, como si él no formase parte de su visión. ${ }^{24}$

${ }^{24}$ Paradójicamente, la objetividad antropocéntrica conduce a la exclusión del punto de vista humano. Con dificultad, incapaces de comprenderla, habíamos fantasiado una Inteligencia Angélica. Luego pecamos volviendo al 'Hombre, medida de todas las cosas'. Pero la contradictio in adjectio de una Inteligencia Artificial es el artificio contra natura de un paradigma inhumano rector de lo humano. Claro, es el correlato de una vida emotiva también fabricada, por máquinas o químicos. Aristóteles decía que el que roba para cometer adulterio es más adúltero que ladrón; quién sabe qué dictaminaría de este desliz al cuadrado (o al cubo) de sustituir la sabiduría por la filosofía, por el conocimiento, por la información, por el hardware... 


\section{ALBERTO SAURET}

Esta crítica al antropocentrismo de nuestra mentalidad cuenta con un coro bastante nutrido, pero con relación a ciertas ideas que flotan en el ambiente espiritual de esta época son anticipatorias las reflexiones de Aldo Leopold, quien desde los años 30 -en trabajos que posteriormente aparecerán bajo el título The Land Ethic-se manifiesta por "un concepto de 'comunidad' que se extienda a todas las formas de vida y al escenario del medio", para normar una ética que dignifique las formas de existencia comprendidas en "la vida no humana y el medio no viviente", 'esclavizadas' y desprotegidas por los códigos económicos y comerciales vigentes. Dice su comentarista: "Aldo Leopold se ha convertido en algo así como el gurú de un nuevo evangelio de la ecología que desecha las viejas racionalizaciones utilitarias para adoptar una nueva definición de la conservación, que hace hincapié en la armonía del hombre con la tierra." 25

Aunque los antecedentes abundan -siendo el más digno en Occidente el de San Francisco por radical y no antropocéntrico-la preocupación ecológica tiene su acta de nacimiento oficial en la Conferencia de las Naciones Unidas sobre el Medio Ambiente, reunida en Estocolmo en 1972.

Pero una cosa es la ecología en tanto que ciencia y otra el ecologismo, resultante de algunas generalizaciones científicas combinadas con nociones procedentes de doctrinas orientales panteístas y animistas. Tal es el caso de La hipótesis Gaia, escrito por el científico británico James Lovelock en 1974, que presenta a la Tierra como un sistema que funciona como unidad viviente. Biosfera, Atmósfera, mundo viviente e inanimado constituyen un ser vivo al que este autor llama Gaia y que, al igual que el personaje mitológico, cuando es agredida reacciona destructivamente; por el contrario, ayuda a quienes le son leales.

En nuestros días, muchos son los autores que al repetir los cuestionamientos a la estrechez y atomización del racionalismo moderno, que confinan de nuestra cosmovisión no sólo lo inaprehensible por la experiencia y el concepto sino también toda noción sobrenatural, in-

${ }^{25}$ Roderick Nash, "¿Tienen derecho las rocas?", en M. Mooney y F. Stuber, comp., Los humanistas y la política, 1984, México, FCE, p. 143. 
LAS SECTAS Y LOS INSECTOS

voquen sin mayor precisión la necesidad de plantear los problemas desde un 'paradigma holístico'.

Max Weber se refirió al 'desencantamiento del mundo', el siglo precedente Schiller lo había hecho sobre lo que llamó 'desendiosamiento de la naturaleza'. Con sendas expresiones ambos observaban a la historia occidental como la del progresivo constreñimiento espiritual a las apariencias fenomenales, el definitivo divorcio entre hecho y valor que implicaba el imperio de la ratio instrumental y una Weltanschauung inhóspita para lo sagrado. ${ }^{26}$

Una típica concepción 'holística' de lo existente tiene expresión con los siguientes términos: "Durante más del noventa y nueve por ciento del transcurso de la historia humana, el mundo estuvo encantado y el hombre se veía a sí mismo como parte integral de él. Ėl completo reverso de esta percepción en meros cuatrocientos años, o algo así ha destruido la continuidad de la experiencia humana y la integridad de la psiquis humana. Al mismo tiempo, casi ha conseguido arruinar por completo el planeta. La única esperanza (...) yace en el reencantamiento del mundo. (...) Si es que vamos a sobrevivir como especie tendrá que surgir algún tipo de conciencia holística o participativa con su correspondiente formación sociopolítica."27

Pero aún más significativos al respecto son los planteamientos de Gregory Bateson, en tanto que "uno de los principales precursores de lo que bien puede ser un importantísimo cambio del pensamiento occidental, un cambio paradigmático por el que se pasa de una biosfera que excluye lo mental a una biosfera que emerge en y a través de

${ }^{26}$ Cfr. Marcel Gauchet, Le désenchantement du mond, 1985, París, Gallimard, p. vii-viii.

${ }^{27}$ Morris Berman, The Reenchantment of the World, 1981, Ithaca, Cornell U.P., p. 23. "La 'des-secularización del mundo -ha indicado George Weigeles uno de los hechos sociales dominantes de la vida de finales del siglo XX'. (...) 'La revanche de Dieu', como la llamó Gilles Kepel, proporciona una base de identidad y compromiso que trasciende las fronteras nacionales", dice Samuel Huntington ("El conflicto entre civilizaciones", Ciencia Politica, $\mathrm{n}^{\circ} 33,1993$, Bogotá). 


\section{ALBERTO SAURET}

procesos mentales. Las implicaciones de semejante unificación teórica -y vivida- de mente y cuerpo, quedan aún por desarrollar. ${ }^{28}$

Bateson habla de una ciencia a la que llama Ecología de la mente, cuya principal finalidad consiste en "proponer una unidad sagrada de la biosfera que contenga menos errores epistemológicos que las versiones de esa unidad sagrada que han ofrecido las varias religiones de la historia". 29

Según el físico Fritjof Capra en un libro muy celebrado (The Turning Point, 1982, N.Y.), con el alejamiento del paradigma racionalista de impronta cartesiana, la humanidad transitaría por un punto de inflexión desde el que se abrirá una visión del mundo revolucionaria. Pero los sones milenaristas son mucho más acentuados y fantásticos en una obra que ha tenido una extraordinaria acogida masiva y que constituye una referencia obligada para comprender características anímicas determinantes de nuestra época 'posmo', The Aquarian Conspiracy, texto canónico de la New Age.

Theilhard de Chardin, para quien el género humano está llamado a ascender hasta el punto de unificación Omega ${ }^{30}$ utilizó la palabra 'conspiración' en su sentido literal, que significa 'respirar juntos', y que será adoptada por Marilyn Ferguson, autora del trabajo que comentamos.

Según los conspiradores acuarianos estaríamos entrando en una Nueva Era (la denominación New Age pertenece a Alice Ann Bailey, fundadora del grupo teosófico Escuela del Arcano) superadora de la 'era de Piscis', que es la Cristiana (ikhtys, que en griego significa 'pez', coincide con las siglas de: Jesucristo, hijo de Dios, Salvador)

${ }^{28}$ Rodney Donaldson en Gregory Bateson, Una unidad sagrada. Pasos ulteriores a una ecología de la mente, 1993, Barcelona, Gedisa, Introducción, p. 18. Subrayado mío.

${ }^{29}$ Ibid.

${ }^{30} \mathrm{Al}$ que le lloverán críticas desde el mismo pensamiento cristiano por los 'extravíos materialistas' de su espiritualidad, p. ej. Dietrich Von Hildebrand en El caballo de Troya en la Ciudad de Dios. 
que abriría la mente a una nueva sensibilidad para comprender la relación de uno con el universo.

"El ciclo astrológico de Piscis, coincidente con la era cristiana -que estaría llegando a su ocaso (...)- se habría caracterizado por "el dolor, el fanatismo, el escepticismo, el conformismo', males necesarios de una época que, al mismo tiempo, trataba de desarrollar el idealismo, la compasión, el espíritu de sacrificio. En conjunto, la edad de Piscis ha sido dominada por el materialismo. En la de Acuario, en cambio, se daría un vuelco, el instaurarse de 'un nuevo nivel de conciencia' por el cual un gran numero de personas vivirá con sabiduría y amor, en una fundamental unidad interior y con el cosmos entero." 31

La New Age habla también del retorno de Cristo, pero no es el Cristo de la doctrina cristiana sino el Cristo cósmico de la tradición esotérica del que, entre otras sectas, hablan las teosóficas. La Teosofía, fundamental para el imaginario de la New Age, tuvo origen en Estados Unidos el siglo pasado y su finalidad es descubrir un núcleo de verdad común a todas las religiones y asociarlo con un oculto saber primordial de la humanidad.

En el ambiente relativista y global generado por la 'cultura mediática', la New Age se ofrece con un talante laxo y ecuménico, contrapuesto a las sociedades religiosas eclesiales, consideradas dogmáticas y sectarias: "Es imposible contener la verdad en una sola iglesia", pontifica su nuevo magisterio. Pero la tolerancia irrestricta de la New Age y su creencia de que la verdad puede alcanzarse por muchas vías ejemplariza la posición clásica de la gnosis, que al relativizar todas las religiones da lugar a los más extraños ensambles sincréticos. A esta enorme amplitud la encontramos también en un remoto movimiento consagrado a las disciplinas ocultas e iniciáticas, la Antigua y Mística Orden de los Rosacruces (AMORC), con sede actual en San José, California, cuya divisa es "la más amplia tolerancia en la más estricta independencia". 32

${ }^{31}$ Antonio Baggio, Che cos'è l'età dell 'Acquario, 1991, Turín, p. 7.

${ }^{32}$ Cfr. Blas Carmona, op. cit., p. 61. 


\section{ALBERTO SAURET}

Pero el sincretismo de este nuevo milenarismo esotérico virtualmente no tiene límites. Además de los mencionados, cuenta como antecedentes con influencias contraculturales (en tanto que transgresores de las convenciones predominantes) provenientes del espiritismo, ocultismo, trascendentalismo, mind-cure, beatniks, hippies y, especialmente, del Esalen Institute, fundado en Big Sur, California, en 1962. Siendo rasgos característicos de su constitución: "emocionalismo, orientalismo, milenarismo, ocultismo, subjetivismo, pelagianismo (...) panteísmo, indigenismo, gnosticismo, psicologismo, ecologismo, pacifismo (...) feminismo, universalismo, anarquismo, monismo y otros". 33

Se trata de una reacción irracionalista que bajo la influencia de la teología radical postconciliar transforma la esperanza escatológica cristiana operando un reduccionismo inmanentista de lo sagrado. No constituye un movimiento estructurado ni, estrictamente, una ideología, iglesia, religión o secta, sino una indefinida atmósfera espiritualista.

"El gran acierto de la New Age consiste en presentarse como un sistema de pensamiento 'abierto', con una gran capacidad de integrar corrientes muy diferentes, que apenas tienen entre sí leves concomitancias", dice Ernesto Milá. ${ }^{34}$

50 En este ambiente blando, light, de permisividad casi irrestricta, donde en 'buena onda' ('take it easy') no tienen cabida las contradicciones excluyentes, brotan las manifestaciones más disímbolas, es decir, subdivisiones sectarias. Por ejemplo, Robert Coon, tataranieto de Joseph Smith, fundador de los mormones, sostiene que morimos porque permitimos que nuestro pensamiento, que tiene un poder ilimitado, se impregne con la idea de la muerte hasta identificarse con ella. Su escuela ofrece el método para lograr la vida eterna.

Por otra parte encontramos que a las viejas prácticas espiritistas ahora se les llama channeling y a los médiums, channelers, auténtica epidemia bajo el clima New Age. "Los hay que reciben mensajes de

${ }^{33}$ Roberto Bosca, New Age, la utopia religiosa de fin de siglo, 1995, Buenos Aires, Atlántida, p. 39.

34 "El triunfo de lo irracional", El viejo topo, I/97, Madrid, p. 42-56. 
Cristo, otros de Maitreya (la futura encarnación de Buda); una ex-ama de casa norteamericana recibió desde 1977 mensajes telepáticos de 'Ramtha', un 'guerrero de la Atlántica' que vivió hace 35,000 años y que predecía todo tipo de catástrofes, ninguna de las cuales se produjo... lo cual no obstaculizó que la ex-ama de casa devenida channeler patentara la marca 'Ramtha' y cobrara 100 dólares por sesión de videncia." 35

Feuerbach dictaminaría que la idea de Dios es reificación de las que se ven como excelencias humanas; y Marx que la religión es el opio de los pueblos. A pesar de sí mismos -y en los límites de lo estrictamente ontológico- ambos tuvieron razón, y continúan con ella. E1 advenimiento de la New Age es inmejorable circunstancia para verificarlo, dado que ésta aparece como clara proyección de las carencias, excesos e ignorancia de un tipo antropológico mezcla de escepticismo, ingenuidad y hedonismo.

Toda búsqueda de conocimiento es de salvación, más claramente en la última frontera. La renuencia a instancias - literalmente-pontificias, convictas de no actuar como mediadoras sino mediatizadoras, en procura de una relación directa con lo sagrado, ${ }^{*}$ donde la superposición de lo religioso con lo psicológico reduce a la religión a una técnica personal o impartida por un instructor, indica que junto a las incertidumbres que 'históricamente' se han buscado colmar con las incursiones religiosas, el aislamiento y anomia de las sociedades actuales demanda métodos paliativos para los ya endémicos procedimientos de soledad, abandono, inseguridad, desorientación, angustia y depresión.

En cuanto a la promiscuidad de supermercado que engloba la $\mathrm{New}$ Age, es fiel reflejo de una mentalidad que no resiste límites ni compromisos; no disputa espacios, los abarca todos; no excluye, compatibiliza: revierte, adapta, desnaturaliza, neutraliza, metaboliza, recicla. Bajo el abigarramiento orgiástico, la completa pérdida de sentido de las partes,

\section{${ }^{35}$ Ibid.}

* Influencia del budismo: religiosidad predominantemente práctica, sin complejidades litúrgicas ni teológicas. 


\section{ALBERTO SAURET}

la ausencia, el vacío. La abundancia y diversidad de 'opciones', correlativa a una actitud de 'guardarropía' diría Ortega (modelo para armar; cuando me canso cambio de look), exhibe asimismo una total ausencia de conciencia histórica y de conciencia sin más; como si uno pudiera ir por la vida impunemente escogiendo según las ganas entre danzar con lobos o sentarse en la posición del loto frente a un buda de yeso.

Las elaboraciones religiosas son parte del espíritu objetivo, es decir, sus complejidades y sutilezas son contraparte de la autoconciencia. Sin menoscabo de otras respuestas a este misterio que llamamos la vida, creo que la riqueza del cristianismo puede ofrecer discreto sosiego a los requerimientos más exigentes por lo absoluto.

Hace unas décadas la contestación juvenil estaba nutrida de ideas filosóficas y políticas que refrescaban la vieja utopía de una sociedad más libre, más justa y más feliz. Hoy este tipo de ideas se rechazan, sin problematizarse, precisamente por 'utópicas', al tiempo que en una actitud mucho más irreflexiva, sentimental e infantil se abrazan doctrinas que, por lo menos, son más burdas.

Me parece que la búsqueda anterior fue más inteligente porque implicaba la idea de crecimiento mediante el disenso, la imaginación y la construcción. Sin subestimar las interferencias del marketing comercial y político, desde luego, en las mutaciones anímicas a la vista, me parece asimismo advertir que la 'nueva conciencia' New Age se abre paso por un espacio mental compartido más determinista, conformista y consumista, correspondiente a un espíritu más embrutecido y elemental, mejor amaestrado.

Una anécdota con símbolo y moraleja. En 1967 Abbie Hoffmann y Jerry Rubin politizan la contestación hippie fundando el partido Yippie (Youth International Party). A mediados de los 80, el primero continúa en el activismo contracultural -p. ej. trabajando a favor de la causa sandinista. El otro en 1980 lanzó el movimiento Yuppie (Youth International Party).

Asociaciones de estudiantes los invitan con frecuencia a las universidades donde, desde sus respectivas tarimas, enfrentan sus posturas en 
medio de un auditorio cómplice. Cada uno cobra unos 1500 dólares por participación.

Cuando Jerry Rubin era teórico de la revolución desde la Universidad de Berkeley escribirá Do it!, para decir: "Los adultos te han llenado de prohibiciones que tú has llegado a ver como naturales: trabaja, estudia, no forniques, no te drogues, pero tú haz exactamente lo contrario. Fuera de la escuela y del trabajo. No creas a nadie mayor de 30 años."

Este mismo personaje en 1985 dirá públicamente: "Tenía prohibida la residencia en numerosos estados de este país y era la causa de miles de enfrentamientos entre padres e hijos. En los años 70 me afeité la barba y nadie ha vuelto a reconocerme en la calle. Hoy ya no salgo de mi domicilio sin antes comprobar si llevo encima mi tarjeta American Express. (...) En los años 60 nadie prestaba atención a su cuerpo, ni nadie se preocupaba por las cuestiones de la salud. Se consumían drogas, se comía mal, ni siquiera se pensaba en la forma física. En los años 70 fue cuando nos dimos cuenta de la importancia de todo esto. (...) Me ocupo de mi cuerpo revolucionariamente. (...) Para triunfar en América hay que introducirse en el sistema financiero. No se puede triunfar sin dinero. (...) Tuvimos que aprender todo lo relacionado con el dinero como se aprende una lengua extranjera. Yo me fui a trabajar a Wall Street y aprendí finanzas. $\mathrm{Y}$ he escrito un libro para que la gente aprenda lo necesario." 36

Cuando compartían ideas, proyectos y actividades ambos estuvieron muy próximos a Timothy Leary, ${ }^{37}$ un profesor de Harvard que siguiendo las experiencias reveladas por Aldous Huxley en The Doors

${ }^{36}$ En entrevista con Daniel Cohn-Bendit, La revolución y nosotros, que la quisimos tanto, 1986, Barcelona, Anagrama, p. 27-48.

37 "Timothy Leary, el gurú del LSD en la década de los sesenta e icono de Internet en los noventa, hizo su último viaje al ser lanzadas este lunes sus cenizas al espacio exterior desde las Islas Canarias en un satélite (...) en lo que es el primer funeral espacial. (...) 'Timothy fue un pionero del espacio y quería viajar a la estratosfera, ahora lo hará', dijo Carol Rosin, amiga cercana a Leary, quien estuvo a su lado cuando éste murió de cáncer" ( $L a$ Jornada, 27/IV/97, p. 27). 


\section{ALBERTO SAURET}

of Perception se proclamará Gran Sacerdote de la nueva religión del ácido, basada en los efectos producidos por la ingestión de LSD, alucinógeno sintetizado en aquellos años, de gran aceptación entre los hippies. Bajo los efectos de las drogas alucinógenas - que al disminuir el azúcar cerebral reducen la racionalidad lógica- llegan a perderse las fronteras de la individualidad, experimentándose una especie de 'conciencia trascendental de fusión con el Todo'. Por ignorancia religiosa y psicológica, muchas veces se llegaría a pensar que las drogas realmente transportaban a un plano superior y las alucinaciones serían confundidas con visiones sobrenaturales propias de las experiencias místicas. Las advertencias de San Juan de la Cruz deberían servir para reconocer los ídolos emanados de una extraviada ebrietas.

"Ya en los siglos XVIII y XIX, algunos hombres percibieron la necesidad de crear un equivalente de lo que en el pasado significara la religión. Robespierre, por ejemplo, intentó crear una nueva religión artificial, pero hubo de fracasar debido a (el trasfondo de materialismo iluminista y al culto idolátrico que la inspiraban). De manera semejante las ideas de Comte acerca de una nueva religión y su positivismo hicieron igualmente imposible alcanzar una respuesta satisfactoria. En muchos respectos, el socialismo de Marx fue, en el siglo XIX, el más importante movimiento religioso popular, aunque formulado en términos seculares." 38

En el nuestro, saturado de cientificidad, una voz influyente sobre las corrientes secularistas, expresión de un reduccionismo biologicista y pragmatista, como la de Julian Huxley, dirá: "La visión evolucionista nos permite discernir los grandes lineamientos de la nueva religión que, podemos estar seguros, habrá de nacer para responder a las necesidades de la próxima era." 39

"Dios no pudo convivir con la filosofía: ¿puede la filosofía vivir sin Dios? Desaparecido su adversario, la Metafísica deja de ser la ciencia de las ciencias y se vuelve lógica, psicología, antropología, historia,

${ }^{38}$ Erich Fromm, La revolución de la esperanza, 1970, México, FCE, p. 130. 39 1965, Religion sin revelación, Buenos Aires, Sudamericana, p. 28. 
economía, lingüística. Hoy el reino de la filosofía es ese territorio cada vez más exiguo, que aún no exploran las ciencias experimentales. $\mathrm{Si}$ se ha de creer a los nuevos lógicos es apenas el residuo no-científico del pensamiento, un error del lenguaje. Quizá la Metafísica de mañana, si el hombre venidero aún siente la necesidad del pensar metafísico, se iniciará como una crítica de la ciencia tal como en la antigüedad principió como crítica de los dioses. Esa Metafísica se haría las mismas preguntas que se ha hecho la filosofía clásica pero el lugar, el desde, de la interrogación no sería el tradicional antes de toda la ciencia sino un después de las ciencias." ${ }^{\text {40 }}$

En este punto, es decir, ya casi para finalizar, encontramos oportuna, rara e interesante la recuperación que - posiblemente influido por Jacques Muglioni-- hace Regis Debray de Auguste Comte, del que dice que con sus distinciones entre verdad y valor se muestra mucho más lúcido que la mayoría de los pensadores postmodernos.

"Comte, sin duda, habría visto en (las) visiones tecnocráticas una enésima y 'anormal insurrección del espíritu contra el corazón'. Ya consideraba que el siglo XX sería un siglo religioso. Si se aventuró, no sin generosidad, a imaginar una religión, la de la Humanidad una e indivisible, susceptible de enterrar 'el cadáver de la guerra' y de establecer la paz universal, al menos sabía que la religión sobrevive muy bien a la muerte de Dios, entidad socialmente accesoria. Al contrario de lo que más tarde se denominaría positivismo, él era plenamente consciente de la impotencia de la ciencia para constituir la unidad espiritual del género humano." 41

Es que, por más repliegues que le descubramos, en cuanto explicación, la racionalidad causal tiene un límite, luego sobreviene la mueca de querer ver qué hay detrás del espejo (la manía de dar vuelta el calcetín).

${ }^{40}$ Octavio Paz, Corriente alterna, 1975, $8^{\text {a }}$., México, Siglo XXI, p. 125.

${ }^{41}$ Regis Debray, El arcaísmo posmoderno, 1996, Buenos Aires, Manantial, p. 46-7. 


\section{ALBERTO SAURET}

Cassirer habla de un proceso religioso-antropológico que transcurre entre los dioses del instante y la noción de Dios personal, trascendente. El camino transitado por Occidente posteriormente ha sido el de un vaciamiento de este concepto hasta su pura formalidad. Es decir, por una especie de dialéctica de la razón pura, que conduce hasta el vaciamiento de las entrañas, se ha operado un proceso de crecimiento en complejidad de la idea de Dios, de elaboración teológica, pero también de extrañamiento y expulsión del Dios vivo del corazón del hombre. Éste en mítico ricorso postcristiano reaparece enajenado, como parodia virtual de fetiches a la carta. Corolario obligado del antropocentrismo solipsista, es el rebote multiplicado de sus ecos en el vacío solitario donde siempre ha discurrido.

Marx, Nietzsche, Freud nos entrenaron para el recelo, pero desconfiar tiene sentido en cuanto nos conduce a una visión más confiable, de lo contrario, bajo el síndrome de la conspiración nos disgregamos sin fin.

Cassirer llama al hombre, 'animal simbólico'. Sus primeros símbolos están cargados de sentido sacro no sólo por carencia expresiva sino por incontaminada intuición metafísica. 'Arcaico' no es lo superado sino el sustrato, no lo perimido sino lo profundo.

56 Freud nos enseñó que cuando reprimimos una pulsión ésta rebrota transferida y deforme. ¿Edípico? ¿Narcisista? ¿Prometéico? ¿Fáustico? quién sabe qué figura acomoda mejor al complejo que le impidió ver que esto también se aplica a la pulsión religiosa. ¿O cómo llamarle a esa desmesura irredimible por todo ejercicio de conciencia, por todo vértigo de poder, por todo reino de este mundo? 